\title{
THE RELATIONSHIP AMONG REPEATED SPRINT AND CHANGE OF DIRECTION ABILITIES IN FOOTBALL PLAYERS WITH CEREBRAL PALSY
}

\author{
Matías Henríquez $^{1}$, Marco Kokaly ${ }^{2}$, Felipe Herrera ${ }^{3}$, and Raul Reina ${ }^{4}$ \\ ${ }^{1}$ National Rehabilitation Centre Pedro Aguirre Cerda, Santiago, Chile \\ ${ }^{2}$ School of Kinesiology, Finis Terrae University, Santiago, Chile \\ ${ }^{3}$ Viña del Mar University, Viña del Mar, Chile \\ ${ }^{4}$ Miguel Hernández University, Sports Research Centre, Elche, Spain
}

Original scientific article

DOI: $10.26582 / \mathrm{k} .52 .2 .6$

\begin{abstract}
:
This study aimed to describe and determine relationships between repeated sprint and change of direction abilities in football players with cerebral palsy according to four sport classes (FT5 to FT8). Seventeen male football players with cerebral palsy took part in this study $(23.0 \pm 4.7$ years, $65.9 \pm 9.5 \mathrm{~kg}, 168.8 \pm 5.9 \mathrm{~cm})$. The repeated sprint ability ( $6 \times 40$-m sprints with a 20 -second recovery) was evaluated to determine the best sprint time, mean sprint time, and percentage of sprint decrement. The difference in lactate concentration was determined using blood samples taken three minutes before and after testing. The Illinois Agility Test (IAT) was also used to assess players' change of direction ability. The FT8 players had better performance $(\mathrm{p}<.01)$ in the best sprint time, mean sprint time and in the IAT scores compared to the players of the sport classes FT5/6. Players of the sport class FT7 also reached higher performance in the IAT compared to the players of the sport classes FT5/6 $(\mathrm{p}<.05)$. A significant correlation was found between the best sprint time and mean sprint time $(\mathrm{r}=.94, \mathrm{p}<.01)$, the best sprint time and the IAT $(\mathrm{r}=.62, \mathrm{p}<.01)$, and between the best sprint time and the difference in lactate concentration $(\mathrm{r}=-.51, \mathrm{p}<.05)$. The relationships between repeated sprint and change of direction abilities demonstrate the performance profile of para-footballers with cerebral palsy in those variables according to their sport classes, exhibiting lower performance than the values reported for regular football players.
\end{abstract}

Key words: physical performance, para-sport, brain impairment, Paralympic sport

\section{Introduction}

Cerebral palsy (CP) football is a para-sport for people with brain impairments, such as $\mathrm{CP}$, traumatic brain injury, or stroke. In order to have a fair competition, $\mathrm{CP}$ football players (CPFP) must present an eligible impairment of hypertonia, ataxia, or athetosis, and they are classified according to the extent to which the impairment impacts the performance of the required football skills (Reina, 2014). Players in the sport classes FT5 and FT6 are considered as those of the lower classes (i.e. two players of these sport classes should be in the field of play), with moderate involvement of spastic diplegia and athetoid/ataxic quadriplegia, respectively. Players of the sport class FT7 are those with moderate spastic hemiplegia, while FT8 players have the minimal impairment criteria to play CP football, and only one player of this sport class can play during a game.

Competition physical performance of CPFPs has been recently described (Boyd, et al., 2016;
Yanci, Castillo, Iturricastillo, \& Reina, 2017; Yanci, Castillo, Iturricastillo, Urbán, \& Reina, 2018; Reina, Iturricastillo, Castillo, Urbán, \& Yanci, 2020). During a match (two halves of 30 minutes each), CPFP cover a mean total distance of $4342 \mathrm{~m}(\mathrm{SD}=1808.4 \mathrm{~m})$, but only $148 \pm 97.4 \mathrm{~m}$ are performed at high speed (Yanci, et al., 2017). Additionally, Boyd et al. (2016) demonstrated that only around six sprints were performed during the games, with a mean distance of $13 \mathrm{~m}$. These results are lower compared to players without disability (i.e. regular football), in which physical demands are higher considering the dimensions of the field of play or the number of players during the game (Mallo, Mena, Nevado, \& Paredes, 2015).

In general, playing football demands execution of large movement patterns during the game using different energetic systems, which requires good physical condition and specific sport skills, so this activity is categorized as intermittent (Morgans, 
Orme, Anderson, \& Drust, 2014). The ability to perform repeated sprints (RSA) is considered a fundamental physical demand in a complex sport like football (da Silva, Guglielmo, \& Bishop, 2010; Gharbi, et al., 2014). Along with this, RSA is required in many situations of the game, and its performance is influenced by physical and physiological components, the role-position during the game, or the level of training (Morcillo, et al., 2015). During the realization of RSA, energetic systems and metabolic and neural factors are fundamental for the modulation of peripheral fatigue (Bishop, Girard, \& Mendez-Villanueva, 2011; Rampinini, et al., 2009). Studies of RSA with regular football players have reported a high concentration of blood lactate values ranging from 10 to $15 \mathrm{mmol} \cdot \mathrm{L}^{-1}$ (Gharbi, et al., 2014), supporting the contribution of the glycolytic anaerobic energetic system to the performance (Dardouri, et al., 2014; Gharbi, et al., 2014). Therefore, the neurological nature of the eligible impairments in CPFP should influence the production and use of lactate in motor activities at a high intensity. Although the lower performance of individuals with $\mathrm{CP}$ has been demonstrated for cardio-respiratory fitness, energy expenditure, anaerobic endurance, muscle strength, agility, stability, and flexibility (e.g. García, et al., 2016; Kloyiam, Breen, Jakeman, Conway, \& Hutzler, 2011), no previous study explored the blood lactate concentration after the performance of RSA in individuals with $\mathrm{CP}$, specifically in para-footballers.

Change of direction ability (CODA) is another relevant requirement in football, described as the capacity to change direction while sprinting over a pre-planned course (Reina, Sarabia, Yanci, García-Vaquero, \& Campayo-Piernas, 2016; Reina, Sarabia, Caballero, \& Yanci, 2017). The relationship between CODA and RSA has been demonstrated in young football players without disability (Spencer, Pyne, Santisteban, \& Mujika, 2011), but no previous research in this topic has been conducted with athletes with CP. Yanci et al. (2018) examined the match load in CPFP during an official competition, demonstrating differences between sport classes; that is, the players of the FT8 sport class demonstrated better performance in outcomes such as maximum velocity and high accelerations and decelerations (Reina, et al. 2020). In particular, the Illinois Agility Test (IAT) involves specific components of acceleration, deceleration, sprint, and changes of direction. The IAT has been recently used in CPFP (Reina, et al., 2016), also demonstrating that those players in the FT8 sport class exhibit better performance than their parasport counterparts, as well as when dribbling the ball is required (Reina, et al., 2017).

In general, individuals with CP have a different/ lower response to exercise than individuals without disability, characterized by a mixture of metabolic and neural factors that affect their physical performance of strength and power (de Groot, et al., 2012), aerobic performance (de Groot, et al., 2012), anaerobic performance (Yanci, et al., 2016), or jump capacity (Reina, Iturricastillo, Sabido, CampayoPiernas, \& Yanci, 2018; Yanci, et al., 2014). In addition, some studies have explored the response to exercise considering the profile (i.e. type and severity of the impairment) of the individuals with CP (de Groot, et al., 2012; Kloyiam, et al., 2011). However, to the best of the authors' knowledge, the relationships between RSA (assessed by the blood lactate concentration) and CODA in CPFP are unknown. A better understanding of these relationships would allow the optimization of training methods used with these para-athletes considering their sport profile (i.e. sport class). Therefore, this study aimed to describe the relationships between RSA and CODA in CPFP according to their sport profiles, under the hypothesis that positive correlations and differences between the sport classes (i.e. FT8 would exhibit better performance) would be determined.

\section{Methods}

\section{Participants}

Seventeen international male football players with CP from the Chilean national team took part in this study (Table 1). This sample size was determined according to a previous study with CPFP (Yanci, et al., 2016), which demonstrated that a sample of a minimum of 15 participants might be enough in this population $\left(\alpha=.05 ; 1 . \beta=0.8 ; \mathrm{p}^{2}=.40\right)$. The sample for this study was determined for convenience, based on the total of players presented in the national team who met the following inclusion criteria: i) a field player, ii) a member of the national team, and iii) confirmed sport class. Due to a small distribution

Table 1. Descriptive data (mean \pm standard deviation) of the study sample

\begin{tabular}{lcccccc}
\hline Sport class & $\mathrm{N}$ & $\begin{array}{c}\text { Body height } \\
(\mathrm{cm})\end{array}$ & Body mass $(\mathrm{kg})$ & BMl $\left(\mathrm{kg} / \mathrm{m}^{2}\right)$ & $\begin{array}{c}\text { Experience } \\
\text { (year) }\end{array}$ & $\begin{array}{c}\text { Training } \\
\text { sessions (N) }\end{array}$ \\
\hline FT5/6 & 4 & $168.5 \pm 1.7$ & $69.6 \pm 6.8$ & $24.5 \pm 2.1$ & $10.3 \pm 2.6$ & $5.3 \pm 1.0$ \\
FT7 & 9 & $167.4 \pm 6.5$ & $62.8 \pm 10.1$ & $22.4 \pm 3.7$ & $9.0 \pm 2.5$ & $4.2 \pm 0.4$ \\
FT8 & 4 & $172.0 \pm 6.9$ & $69.3 \pm 10.5$ & $23.3 \pm 1.8$ & $10.0 \pm 3.4$ & $4.3 \pm 1.0$ \\
Overall & 17 & $168.8 \pm 5.9$ & $65.9 \pm 9.5$ & $23.1 \pm 3.0$ & $9.5 \pm 2.6$ & $4.5 \pm 0.8$ \\
\hline
\end{tabular}


of players in the sport classes FT5 and FT6, their data were combined (i.e. FT5/6) as suggested by other studies (e.g. Boyd, et al., 2016), and they were considered as the players with the lower class for the game. All the participants were notified of the research purpose and signed an informed consent form. A local university ethics committee approved this study (ID. 152018).

\section{Procedures}

A cross-sectional study was conducted. The RSA, lactate concentration, and CODA measurements were performed on an outdoor football field with synthetic grass. All the participants were instructed to perform their maximum effort during testing, and their last meal was taken at least three hours in advance. Participants were also instructed to avoid any intake of caffeinated drinks for at least eight hours and intense exercise for at least 24 hours before testing (Gharbi, Dardouri, Haj-Sassi, Chamari, \& Souissi, 2015; Rampinini, et al., 2009).

The RSA protocol measures the repeated sprint and the ability to perform changes of direction (Impellizzeri, et al., 2008). Athletes were instructed to sprint at their maximum effort in a trajectory of $40 \mathrm{~m}\left(20 \mathrm{~m}\right.$ sprint forth + turn of $180^{\circ}+20 \mathrm{~m}$ sprint back). The sprints were performed six times, separated by 20 seconds of passive recovery between the trials. Two time gates (PEM10D, Velleman, Gavere, Belgium) were used for testing, placed at the starting and change-of-direction lines. The RSA variables were the best time in a single sprint $\left(\mathrm{RSA}_{\text {Bes }}\right)$, the mean time for all the sprints $\left(\mathrm{RSA}_{\text {Mean }}\right)$, the percentage of performance decrement across all sprints (Eq. 1) (Shalfawi, Enoksen, \& Tønnessen, 2014), and the first $\left(\mathrm{RSA}_{1}\right)$ and the last $\left(\mathrm{RSA}_{6}\right)$ sprint scores. two 10-m sprints to finish the CODA course (see course in Reina, et al., 2016). The participants were instructed to exert the maximum effort to perform the test in the shortest time, measured with two time gates at the starting and finishing lines (PEM10D, Velleman, Gavere, Belgium). Three repetitions were performed with a 3-minute rest interval between the trials, and the best trial was used for statistical analyses $\left(\mathrm{IAT}_{\text {Best }}\right)$.

\section{Statistical analysis}

The data are expressed as mean and standard deviation (SD), and the distribution of each variable was verified by the Shapiro-Wilk's normality test. The strength of associations between the variables was examined by the Pearson coefficient (r) and interpreted as follows: $\leq .10$, trivial; .10-.30, small; .30-.50, moderate; .50-.70, large; .70-.90, very large; and $>.90$, almost perfect (Hopkins, Marshall, Batterham, \& Hanin, 2009). A one-way analysis of variance was also performed between the sport classes including the Tukey's test for pair comparisons. The Hedges' $g$ index was used to calculate effect sizes between sport classes (Hedges $\&$ Olkin, 1985). This index is based on Cohen's $d$ index (Cohen, 1988), but it provides an effect size estimation reducing the bias caused by small samples $(\mathrm{n}<20)$. Hedges' $g\left(d_{\mathrm{g}}\right)$ was interpreted according to Rhea's (2004) proposal for professional or well-trained athletes: above 1.00 , between 0.50 and 1.00 , between 0.25 and 0.50 , and lower than 0.25 were considered large, moderate, small, and trivial, respectively. The results were analyzed with GraphPad Prism v.6 (San Diego, CA, USA). The level of significance was set at $\mathrm{p}<.05$.

$$
\text { RSA Dec } \%=\left\{1-\frac{(\text { RSA } 1+\text { RSA } 2+\text { RSA } 3+\text { RSA } 4+\cdots+\text { RSA final })}{\text { RSA Best } \times \mathrm{N}^{\circ} \text { Sprints }}\right\} \times 100
$$

Before the beginning of the RSA test and after three minutes of passive recovery after the test has been finished, blood lactate concentration [(La) $\left.\mathrm{mmol} \cdot \mathrm{L}^{-1}\right]$ measurement samples were taken from the athlete's earlobe (Lactate Pro 2, Arkray, Tokyo, Japan). The difference in the lactate values before and after the RSA was calculated $\left[\Delta(\mathrm{La}) \mathrm{mmol} \cdot \mathrm{L}^{-1}\right]$ (Gharbi, et al., 2014, 2015).

With regard to CODA, the IAT was used to determine the time needed to complete performance in a determined circuit: (1) the athlete sprints $10 \mathrm{~m}$ forth, (2) turns, and (3) returns to the starting line; after returning to the starting line, (4) the athlete swerves in and out of four cones, $(5,6)$ completing

\section{Results}

With regard to the RSA performance, Figure 1 shows the scores from the 17 CPFPs of this study. Sprint 1 had the best performance $(8.59 \pm 0.46 \mathrm{~s})$, while sprint 2 had a similar mean score $(8.60 \pm 0.61$ s). Both sprints 1 and 2 significantly differed from the other four sprints of the RSA testing, with higher differences in sprint $6(9.18 \pm 0.64 \mathrm{~s})$. The percentage of decrement in all the sprints was $4.73 \pm 2.35 \%$. According to the sport classes, FT5/6 players demonstrated a decrease in their performance of $5.07 \pm 1.52 \%$, FT7 of $4.56 \pm 2.52 \%$, and FT8 of $4.76 \pm 3.16 \%$, without significant differences between the sport classes. 


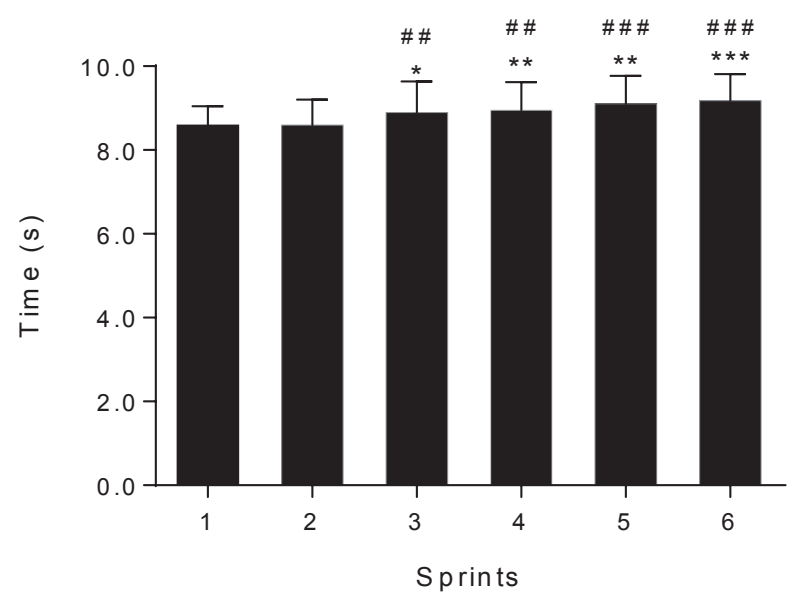

Figure 1. Results of individual performance in the test of repeated sprint ability (RSA). Note: * for sprint 1; * $p<.05$, ${ }^{* *} p<.01$. ${ }^{* * *} p<.001$. \#for sprint $2 ; \# \# p<.01$. \#\#\# $p<.001$.

For the best sprint $\left(\mathrm{RSA}_{\text {Best }}\right)$, FT8 players had better performance compared to FT5/6 players ( $7.96 \pm 0.34$ vs. $9.05 \pm 0.21 \mathrm{~s} ; \mathrm{p}<.01 ; d_{\mathrm{g}}=2.33$, large). Although without significant statistical differences ( $>$ $>05)$ but with large effect sizes $\left(d_{\mathrm{g}}>1.00\right)$, the FT7 players performed better $(8.47 \pm 0.44 \mathrm{~s})$ than $\mathrm{FT} 5 / 6$ players $\left(d_{\mathrm{g}}=2.01\right.$, large $)$ and worse than FT8 players $\left(d_{\mathrm{g}}=1.09\right.$, large). Similar results were obtained for the mean score in the RSA test (overall performance $=8.89 \pm 0.59 \mathrm{~s}$ ). The players of the sport class FT8 showed better performance $(8.34 \pm 0.54 \mathrm{~s})$ than those of the sport classes FT5/6 $(9.51 \pm 0.29 \mathrm{~s})(\mathrm{p}<.01$; $d_{\mathrm{g}}=1.58$, large). Similarly, in the RSA $\mathrm{Best}_{\text {, }}$, the players of the sport class FT7 performed better $(8.85 \pm 0.45$ s) than those in the sport classes FT5/6 $\left(d_{\mathrm{g}}=1.07\right.$, large) but worse than those in the sport class FT8 $\left(d_{\mathrm{g}}=.82\right.$, moderate).

Table 2 shows the results obtained in blood lactate concentration in the RSA test, demonstrating that the overall group and the players from each sport class increased their scores of lactate concentration after the RSA testing $\left(\mathrm{p}<.01, d_{\mathrm{g}}=\right.$ large $)$.

Regarding the performance in the CODA test, the overall group had performance of $17.97 \pm 1.22 \mathrm{~s}$ in the IAT. Considering the sport classes, individuals in the sport class FT8 had better performance $(17.03 \pm 0.60 \mathrm{~s})$ compared to those of the sport classes FT5 $/ 6\left(19.39 \pm 0.88 \mathrm{~s} ; \mathrm{p}<.01 ; d_{\mathrm{g}}=1.95\right.$, large $)$ and FT7 $\left(17.76 \pm 1.03 \mathrm{~s} ; \mathrm{p}>.05 ; d_{\mathrm{g}}=.64\right.$, moderate). In addition, FT7 players had significantly better performance than FT5/6 players $\left(\mathrm{p}<.05 ; d_{\mathrm{g}}=1.43\right.$, large).
Figure 2 shows the correlations among RSA, lactate concentration, and CODA performance.

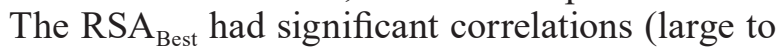
almost perfect) with the change in lactate concentration (2.A: $\mathrm{r}=-.51, \mathrm{p}<.05)$, the performance in the CODA test (2.C: $\mathrm{r}=.62, \mathrm{p}<.01)$, and the performance in sprints 1 (2.E: $\mathrm{r}=-.93, \mathrm{p}<.01)$ and 6 (2.G: $\mathrm{r}=-.74$, $\mathrm{p}<.01)$. Similarly, the mean score in the RSA test $\left(\mathrm{RSA}_{\text {Mean }}\right)$ correlated (moderate to almost perfect) with the change in lactate concentration (2.B: $\mathrm{r}=-.49$, $\mathrm{p}<.05$ ), the IAT (2.D: $\mathrm{r}=.69, \mathrm{p}<.01)$, the performance in sprint 1 (2.F: $\mathrm{r}=-.92, \mathrm{p}<.01)$ and sprint 6 (2.H: $\mathrm{r}=-.90, \mathrm{p}<.01)$, and also with the best RSA sprint (2.J: $\mathrm{r}=-.94, \mathrm{p}<.01)$. In addition, a negative very large correlation was found between sprints 1 and 6 (2.I: $\mathrm{r}=-.73, \mathrm{p}<.01)$. No significant correlations were found for the $\mathrm{RSA}_{\mathrm{Dec} \%}$.

\section{Discussion and conclusions}

This study aimed to describe RSA and CODA in international football players with $\mathrm{CP}$, exploring the relationships between several variables related to anaerobic performance (i.e. blood lactate concentration) and the responses to maximum exertion by players with different functional profiles, that is, $\mathrm{CP}$ football sport classes. To the best of the authors' knowledge, there is no previous study analyzing those relationships or their RSA performance and lactate concentration prior to and after testing in this population. This research demonstrates that CPFPs exhibit differences in their performance according to the sport classes in the $\mathrm{RSA}_{\text {Best }}, \mathrm{RSA}_{\text {Mean }}$, and IAT scores. In addition, several significant relationships have been found between the above-mentioned variables.

The RSA test demands considerable levels of neural activation and muscular power (Girard, Méndez-Villanueva, \& Bishop, 2011). However, the performance of several sprints in a short period is limited due to the human capacity to fully activate the muscles, maintain muscular recruitment, and modulate the presence of fatigue (Girard, et al., 2011). Our study reveals that football players with $\mathrm{CP}$ have lower performance in RSA compared to football players without disability (Impellizzeri, et al., 2008; Pareja-Blanco, et al., 2016; Rampinini, et al., 2009). These results can be explained by the fact that individuals with $\mathrm{CP}$ are compromised in producing muscle power because of their limited

Table 2. Values of blood lactate concentration pre- and post-RSA testing

\begin{tabular}{lccccc}
\hline Sport class & Pre $[\mathrm{La}]\left(\mathrm{mmol} \cdot \mathrm{L}^{-1}\right)$ & Post $[\mathrm{La}]\left(\mathrm{mmol} \cdot \mathrm{L}^{-1}\right)$ & $\Delta[\mathrm{La}]\left(\mathrm{mmol} \cdot \mathrm{L}^{-1}\right)$ & $p$ & $\mathrm{~d}_{\mathrm{g}}$ \\
FT5/6 & $1.18 \pm 0.25$ & $7.80 \pm 0.37$ & $6.63 \pm 0.25$ & $<.01$ & 19.29 \\
FT7 & $1.06 \pm 0.19$ & $11.06 \pm 2.93$ & $10.00 \pm 2.98$ & $<.01$ & 46.78 \\
FT8 & $1.28 \pm 0.10$ & $9.80 \pm 1.49$ & $8.53 \pm 1.51$ & $<.01$ & 61.96 \\
Overall & $1.14 \pm 0.20$ & $9.99 \pm 2.56$ & $8.86 \pm 2.63$ & $<.01$ & 42.14 \\
\hline
\end{tabular}

Note. $d_{g}=$ effect size 

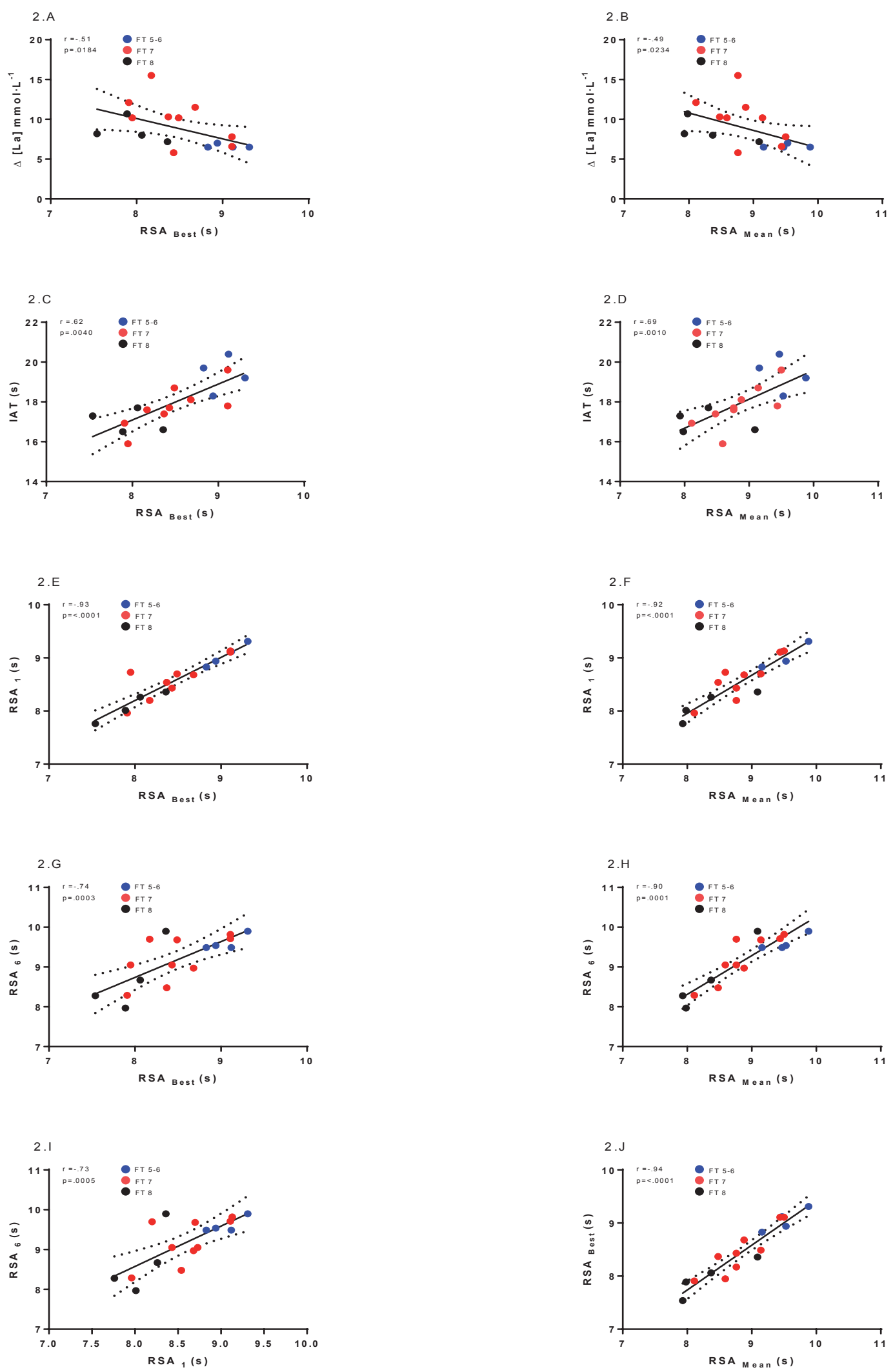

Figure 2. Correlation plots for the repeated sprints ability (RSA), lactate concentration, and change of direction variables.

motor control, muscular weakness, or incomplete recruitment of motor units during voluntary muscular contraction (Graham et al., 2016; Verschuren, Peterson, Balemans, \& Hurvitz, 2016). Other studies involving football players with and without $\mathrm{CP}$ have also demonstrated lower performance by those with CP in actions of high physical demands, such as muscle strength and anaerobic performance (Yanci, et al., 2016), endurance (Kloyiam, et al., 2011), sprint (Reina, et al., 2017), 
high-intensity accelerations and decelerations (Reina, et al., 2020) or jumping capability (Reina, et al., 2018; Yanci, et al., 2014).

During the RSA test, individual times of the first and second sprints were better compared with the performance of the four other sprints. These results are in concordance with previous studies in football players without disability (da Silva, et al., 2010). Along with this, the contribution of the energetic systems to the performance of RSA varies across different sprints and emphasized that the limitation of performance is displayed mainly for peripheral factors (Girard, et al., 2011). In addition, the activation and recruitment of motor units for the RSA performance require higher levels of muscle power, specifically with an increase of the activation of type II fibres in the quadriceps and gastrocnemius (Brocherie, et al., 2014). As a consequence, a higher proportion of type II muscle fibres is presented in spastic muscles (Peterson, Gordon, Hurvitz, \& Burant, 2012), a common feature in CPFP, especially in those of the sport classes FT5 and FT7 and many of the FT8 players. Taking into consideration that spasticity is velocity-dependent (i.e. an increase in muscle tone because of co-contraction of agonist and antagonist muscles) (Sanger et al., 2006), the lower performance in the RSA can also be explained by the constrained function of the fast muscle fibres, including higher changes in phosphocreatine concentration during the first sprints (Girard, et al., 2011). In addition, these fibres have a considerable contribution in the oxidative metabolism to resynthesize and clear metabolic factors that contribute to fatigue development and the failure of muscular contraction (Bishop, et al., 2011; da Silva, et al., 2009; Gharbi, et al., 2014; Girard, et al., 2011). On the other hand, CPFP with ataxia or athetosis (sport class FT6 and some in FT8) would decrease their performance in the RSA because of their worse running economy (Kloyiam, et al., 2011) or the limitation caused by their coordination impairment (Reina, et al., 2016, 2017).

The $\Delta(\mathrm{La})$ scores exhibited by the CPFP of this study were lower compared with football players without disability $\left(10-15 \mathrm{mmol} \cdot \mathrm{L}^{-1}\right)$ (Gharbi, et al., 2014). These lower values in individuals with $C P$ have also been reported in other para-sports for this population, such as $\mathrm{CP}$ football $\left(9.6 \mathrm{mmol} \cdot \mathrm{L}^{-1}\right.$; Denadai, 2002), race running $\left(5.0 \pm 3.7 \mathrm{mmol} \cdot \mathrm{L}^{-1}\right.$; Donnell, Verellen, Van de Vliet, \& Vanlandewijck, 2010), and para-athletics wheelchair runners (9.9 $\pm 2.1 \mathrm{mmol} \cdot \mathrm{L}^{-1}$; Bhambhani, Holland, \& Steadward, 1993). A possible mechanism that contributes to the lower performance in RSA and the lower lactate blood concentration is the influence of the above-mentioned spasticity and muscle co-contraction, decreasing the venous return and altering the reuse of lactate, causing early fatigue and a decrease of muscular resistance (Kloyiam, et al., 2011).
Higher values of blood lactate suggest an important requirement of anaerobic glycolysis during the performance of RSA (Dardouri, et al., 2014), so the lower values of the CPFP in this study can be related to a lower muscle mass activation during motor performance and different muscle phenotypes in people with CP (Graham, et al., 2016; Peterson, et al., 2012). This hypothesis can be supported by the lower values of $\Delta(\mathrm{La})$ and the higher percentage of $\mathrm{RSA}_{\mathrm{Dec} \%}$ of the FT5/6 players compared to the players of the other sport classes, suggesting implications between the type of motor commitment and the lower capacity to perform physical activities with a higher energetic cost in the displacement at different intensities (Boyd, et al., 2016; Kloyiam, et al., 2011; Yanci, et al., 2017).

About the CODA assessment included in this study, the IAT requires accelerations, decelerations, and changes of direction, which are fundamental to the performance during football games (Reina, et al., 2016, 2017, 2020). Players with CP performed at a lower overall score $(17.97 \pm 1.22 \mathrm{~s})$ than in other studies involving regular football players (Kulkarni, Levin, Penailillo, Singh, \& Singh, 2013 $=15.91 \pm 0.67$ s; Reina, et al., $2016=15.31 \pm 0.60 \mathrm{~s})$. In particular, players in the sport classes FT5/6 $(\mathrm{p}<.01)$ and FT7 (large effect sizes) exhibited more difficulties performing sprint actions with acceleration, deceleration, turns, and changes of direction compared with other players with minimal impairments (Reina, et al., 2016, 2017, 2020). It is plausible to think that the presence of an elongated sarcomere and problems with muscular coordination in individuals with $\mathrm{CP}$ may also constrain force production, affecting the necessary components to perform tasks with high agility demands (Graham, et al., 2016).

A negative relationship was found between blood $\Delta(\mathrm{La})$ and RSA, in which the participants with the best performance in RSA presented higher blood values (La). Football players with CP presented a similar relationship as described in football players without a disability, highlighting the contribution of the anaerobic glycolytic metabolism during RSA testing (Dardouri, et al., 2014; Gharbi, et al., 2014). This relationship may be explained by the same mechanism observed in footballers without disability (Girard, et al., 2011), but considering the physical and physiological features of CPFP (Kloyiam, et al., 2011). For example, the relationship between $\mathrm{RSA}_{\text {Best }}$ and $\mathrm{RSA}_{1}$ determines the relevance of the anaerobic components and peripheral factors underlying the RSA performance (Gharbi, et al., 2015; Pareja-Blanco, et al., 2016).

While the performance in the first sprint is relevant and is associated with the maximal sprint capacity, the final sprints are more associated with intermittent endurance (Pareja-Blanco, et al., 2016). Players with the best $\mathrm{RSA}_{\text {Mean }}$ presented the best 
results in the $\mathrm{RSA}_{1}$ and the $\mathrm{RSA}_{6}$, with almost perfectly positive negative correlations. Therefore, the RSA $\mathrm{Rean}_{\text {is }}$ is the principal predictor in this study group, and these results are in concordance with other studies in literature (Bishop, et al., 2011; Pareja-Blanco, et al., 2016). The RSA Mean $_{\text {and the }}$ $\mathrm{RSA}_{\text {Best }}$ also had large positive correlations with the IAT, demonstrating that performing CODA with high physical demands is essential for the execution of technical and tactical actions in CP football (Morgans, et al., 2014; Spencer, et al., 2011). Considering the sport classes, FT8 players demonstrated higher physical capacity in all the RSA and CODA outcomes included in this study, so their superior physical abilities can have an important influence on successful games (Boyd, et al., 2011).

It should be noted that a limitation of this study was a relatively small sample of para-footballers in each sport class. Furthermore, future studies should include muscle power assessments to identify its influence on the capacity to perform RSA in football players with $\mathrm{CP}$.

\section{Practical implications}

This study demonstrates that football players with CP presented lower levels of performance in repeated sprints, lactate concentration, and
CODA compared with previous studies in football players without a disability. Players of the class FT8 presented the best performance compared to others with higher impairments of hypertonia, athetosis, and ataxia. Statistical relationships have been established between repeated sprints ability and CODA, and the $\mathrm{RSA}_{\text {Mean }}$ appears to be the best predictor variable. In addition, negative relationships were found between the best and mean sprints and the increase of lactate concentration after the RSA testing. These results have some practical implications from the coaching and classification perspectives. From the coaching perspective, coaches should adjust the objectives of their RSA training according to the type of players' profiles (i.e. sport classes), but also considering other variables such as the playing position or the displacements executed at high intensity (i.e. GPS records). From the classification perspective, this study reinforces the idea of increasing physical demands during the classification process (i.e. technical assessment stage), in which players with different profiles will demonstrate the impact of their impairment on the performance in the sprint and change of direction testing, helping classifiers in their decision-making for allocating to a sport class.

\section{References}

Bhambhani, Y.N., Holland, L.J., \& Steadward, R.D. (1993). Anaerobic threshold in wheelchair athletes with cerebral palsy: Validity and reliability. Archives of Physical Medicine and Rehabilitation, 74(3), 305-311.

Bishop, D., Girard, O., \& Mendez-Villanueva, A. (2011). Repeated-sprint ability - Part II: Recommendations for training. Sports Medicine, 41(9), 741-756. doi:10.2165/11590560-000000000-00000

Boyd, C., Barnes, C., Eaves, S.J., Morse, C.I., Roach, N., \& Williams, A.G. (2016). A time-motion analysis of Paralympic football for athletes with cerebral palsy. International Journal of Sport Science and Coaching, 11(4), 552-558. doi:10.1177/1747954116654786

Brocherie, F., Girard, O., Forchino, F., Al Haddad, H., Dos Santos, G.A., \& Millet, G.P. (2014). Relationships between anthropometric measures and athletic performance, with special reference to repeated-sprint ability, in the Qatar national soccer team. Journal of Sports Sciences, 32(13), 1243-1254. doi:10.1080/02640414.2013.862840

Cohen, J. (1988). Statistical power analysis for the behavioral sciences. Hillsdale, NJ: Lawrence Erlbaum Associates.

da Silva, J.F., Guglielmo, L.G.A., \& Bishop, D. (2010). Relationship between different measures of aerobic fitness and repeated-sprint ability in elite soccer players. Journal of Strength and Conditioning Research, 24(8), 2115-2121. doi:10.1519/JSC.0b013e3181e34794

Dardouri, W., Selmi, M.A., Sassi, R.H., Gharbi, Z., Rebhi, A., Yahmed, M.H., \& Moalla, W. (2014). Relationship between repeated sprint performance and both aerobic and anaerobic fitness. Journal of Human Kinetics, 40(1), 139-148. doi:10.2478/hukin-2014-0016

de Groot, S., Dallmeijer, A.J., Bessems, P.J., Lamberts, M.L., van der Woude, L.H., \& Janssen, T.W. (2012). Comparison of muscle strength, sprint power and aerobic capacity in adults with and without cerebral palsy. Journal of Rehabilitation Medicine, 44(11), 932-938. doi:10.2340/16501977-1037

Denadai, B.S. (2002). Determinação do limiar anaeróbio em jogadores de futebol com paralisia cerebral e nadadores participantes da paraolimpíada de Sidney 2000. [Determination of the anaerobic threshold in soccer players with cerebral palsy and swimmers participant in the Sidney 2000 Paralympic Games. In Portuguese.] Revista Brasileira de Medicina do Esporte, 8(3), 117-121. doi:10.1590/S1517-86922002000300009

Donnell, R.O., Verellen, J., Van de Vliet, P., \& Vanlandewijck, Y. (2010). Kinesiologic and metabolic responses of persons with cerebral palsy to sustained exercise on a petra race runner. European Journal of Adapted Physical Activity, 3(1), 7-17. 
García, C.C., Alcocer-Gamboa, A., Ruiz, M.P., Caballero, I.M., Faigenbaum, A.D., Esteve-Lanao, J., Saiz, B., Lorenzo, T., \& Lara, S.L. (2016). Metabolic, cardiorespiratory, and neuromuscular fitness performance in children with cerebral palsy: A comparison with healthy youth. Journal of Exercise Rehabilation, 12(2), 124-131. doi:10.12965/ jer.1632552.276

Gharbi, Z., Dardouri, W., Haj-Sassi, R., Castagna, C., Chamari, K., \& Souissi, N. (2014). Effect of the number of sprint repetitions on the variation of blood lactate concentration in repeated sprint sessions. Biology of Sport, 31(2), 151-156. doi:10.5604/20831862.1099046

Gharbi, Z., Dardouri, W., Haj-Sassi, R., Chamari, K., \& Souissi, N. (2015). Aerobic and anaerobic determinants of repeated sprint ability in team sports athletes. Biology of Sport, 32(3), 207-212. doi:10.5604/20831862.1150302

Girard, O., Mendez-Villanueva, A., \& Bishop D. (2011). Repeated-sprint ability - Part 1: Factors contributing to fatigue. Sports Medicine, 41(8), 673-694. doi:10.2165/11590550-000000000-00000

Graham, H.K., Rosenbaum, P., Paneth, N., Dan, B., Lin, J.P., Damiano, D.L., Becher, J.G., Gaebler-Spira, D., Colver, A., Reddihough, D.S., Crompton, K.E., \& Lieber, R.L. (2016). Cerebral palsy. Nature Review. Disease Primers, 2, 15082. doi:10.1038/nrdp.2015.82

Hedges, L.V., \& Olkin, I. (1985). Statistical methods for meta-analysis. San Diego, CA: Academic Press.

Hopkins, W.G., Marshall, S.W., Batterham, A.M., \& Hanin, J. (2009). Progressive statistics for studies in sports medicine and exercise science. Medicine and Science in Sports and Exercise, 41(1), 3-12. doi:10.1249/ MSS.0b013e31818cb278

Impellizzeri, F.M., Rampinini, E., Castagna, C., Bishop, D., Ferrari-Bravo, D., Tibaudi, A., \& Wisloff, U. (2008). Validity of a repeated-sprint test for football. International Journal of Sports Medicine, 29(11), 899-905. doi:10.1055/s-2008-1038491

Kloyiam, S., Breen, S., Jakeman, P., Conway, J., \& Hutzler, Y. (2011). Soccer-specific endurance and running economy in soccer players with cerebral palsy. Adapted Physical Activity Quarterly, 28(4), 354-367. doi:10.1123/apaq.28.4.354

Kulkarni, K., Levin, G.T., Penailillo, L., Singh, A., \& Singh, S.J. (2013). Physical and physiological characteristics of elite Indian national football players. Journal of Athletic Enhancement, 2, 6. doi:10.4172/2324-9080.1000128

Mallo, J., Mena, E., Nevado, F., \& Paredes, V. (2015). Physical demands of top-class soccer friendly matches in relation to a playing position using global positioning system technology. Journal of Human Kinetics, 47(1), 179-188. doi:10.1515/hukin-2015-0073

Morcillo, J.A., Jiménez-Reyes, P., Cuadrado-Peñafiel, V., Lozano, E., Ortega-Becerra, M., \& Párraga, J. (2015). Relationships between repeated sprint ability, mechanical parameters, and blood metabolites in professional soccer players. Journal of Strength and Conditioning Research, 29(6), 1673-1682. doi:10.1519/JSC.0000000000000782

Morgans, R., Orme, P., Anderson, L., \& Drust, B. (2014). Principles and practices of training for soccer. Journal of Sport Health Science, 3(4), 251-257. doi:10.1016/j.jshs.2014.07.002

Pareja-Blanco, F., Suarez-Arrones, L., Rodríguez-Rosell, D., López-Segovia, M., Jiménez-Reyes, P., Bachero-Mena, B., \& González-Badillo, J.J. (2016). Evolution of determinant factors of repeated sprint ability. Journal of Human Kinetics, 54(1), 115-126. doi:10.1515/hukin-2016-0040

Peterson, M.D., Gordon, P.M., Hurvitz, E.A., \& Burant, C.F. (2012). Secondary muscle pathology and metabolic dysregulation in adults with cerebral palsy. American Journal of Physiology, Endocrinology and Metabolism, 303(9), E1085-E1093. doi:10.1152/ajpendo.00338.2012

Rampinini, E., Sassi, A., Morelli, A., Mazzoni, S., Fanchini, M., \& Coutts, A.J. (2009). Repeated-sprint ability in professional and amateur soccer players. Applied Physiology, Nutrition and Metabolism, 34(6), 1048-1054. doi:10.1139/H09-111

Reina, R. (2014). Evidence-based classification in Paralympic sport: Application to football-7-a-side. European Journal of Human Movement, 32, 161-185.

Reina, R., Iturricastillo, A., Castillo, D., Urbán, T., \& Yanci, J. (2020). Activity limitation and match load in parafootballers with cerebral palsy: An approach for evidence-based classification. Scandinavian Journal of Medicine and Science in Sports, 30(3), 496-504. doi: 10.1111/sms.13583

Reina, R., Iturricastillo, A., Sabido, R., Campayo-Piernas, M., \& Yanci, J. (2018). Vertical and horizontal jump capacity in international cerebral palsy football players. International Journal of Sports Physiology and Performance, 13, 597-603. doi:10.1123/ijspp.2017-0321

Reina, R., Sarabia, J.M., Caballero, C., \& Yanci, J. (2017). How does the ball influence the performance of change of direction and sprint tests in para-footballers with brain impairments? Implications for evidence-based classification in CP-football. PLoS One, 12(11), e0187237. doi:10.1371/journal.pone.0187237

Reina, R., Sarabia, J.M., Yanci, J., García-Vaquero, M.P., \& Campayo-Piernas, M. (2016). Change of direction ability performance in cerebral palsy football players according to functional profiles. Frontiers in Physiology, 6, 409. doi:10.3389/fphys.2015.00409

Rhea, M.R. (2004). Determining the magnitude of treatment effects in strength training research through the use of the effect size. Journal of Strength and Conditioning Research, 18, 918-920. doi: 10.1519/14403.1

Sanger, T.D., Chen, D., Delgado, M.R, Gaebler-Spira, D., Hallett, M., \& Mink, J.W. (2006). Taskforce on childhood motor disorders: Definition and classification of negative motor signs in childhood. Pediatrics, 118, $2159-2167$. doi:10.1542/peds.2005-3016 
Shalfawi, S.A.I., Enoksen, E., \& Tønnessen, E. (2014). The relationship between measures of sprinting, aerobic fitness, and lower body strength and power in well-trained female soccer players. International Journal of Applied Sports Sciences, 26(1), 18-25. doi:10.24985/ijass.2014.26.1.18

Spencer, M., Pyne, D., Santisteban, J., \& Mujika, I. (2011). Fitness determinants of repeated-sprint ability in highly trained youth football players. International Journal of Sports Physiology and Performance, 6(4), 497-508. doi:10.1123/ijspp.6.4.497

Verschuren, O., Peterson, M.D., Balemans, A.C.J., \& Hurvitz, E.A. (2016). Exercise and physical activity recommendations for people with cerebral palsy. Developmental Medicine and Child Neurology, 58(8), 798-808. doi:10.1111/ dmen.13053

Yanci, J., Castagna, C., Los Arcos, A., Santalla, A., Grande, I., Figueroa, J., \& Cámara, J. (2016). Muscle strength and anaerobic performance in football players with cerebral palsy. Disability and Health Journal, 9(2), 313-319. doi:10.1016/j.dhjo.2015.11.003

Yanci, J., Castillo, D., Iturricastillo, A., \& Reina, R. (2017). Evaluation of the official match external load in soccer players with cerebral palsy. Journal of Strength and Conditioning Research. Jun 22, Epub ahead of print. doi:10.1519/JSC.0000000000002085

Yanci, J., Castillo, D., Iturricastillo, A., Urbán, T., \& Reina, R. (2018). External match loads of footballers with cerebral palsy: A comparison among sport classes. International Journal of Sports Physiology and Performance, 13(5), 590-596. doi:10.1123/ijspp.2017-0042

Yanci, J., Los Arcos, A., Grande, I., Santalla, A., Figueroa, J., Gil, E., \& Cámara, J. (2014). Jump capacity in cerebral palsy soccer. Revista Internacional de Medicina y Ciencias de la Actividad Física y el Deporte, 14(54), 199-211.

Submitted: November 27, 2018

Accepted: April 16, 2020

Published Online First: Novemeber 25, 2020

Correspondence to:

Matías Henríquez, M.Sc.

National Rehabilitation Centre Pedro Aguirre Cerda, Chile

Phone: +225754360

E-mail: matias.henriquez@redsalud.gob.cl 